${ }^{24}$ Stothers JK. The effect of forced convection on neonatal heat loss. J Physiol (Lon) 1980;305:77.

Correspondence to Dr P J J Sauer, Division of Neonatology, The
Hospital for Sick Children, 555 University Avenue, Toronto, Ontario, Canada M5G 1 X8.

Received 10 October 1983

\title{
Editorial
}

\section{Sunday after the war}

The Sunday after the war was for many children a time to look forward to when all the harrowing experiences would have passed, food would be in abundance, and families united. Delicacies such as oranges and bananas which were known only from their descriptions in books would be on the table for everyone to eat. Since we were going to win the war there would clearly be no shortages of anything afterwards. We spent hours planning what we would eat, what we would do, and whom we would see.

The great day came and went, and apart from a few fireworks and the different content of the 6 o'clock news it was difficult to see any difference between that Sunday and any other Sunday during the previous 6 years. How many times since then have we had the same sensation? The same sequence of events has occurred whenever attempts have been made to improve the child health services in this country. Pressure, both professional and public, has resulted in the setting up of a royal commission and while this has been taking evidence complete lack of progress has been assured. After several years' work the report is published and often is not even discussed by those who commissioned it. Those who look forward to essential changes soon realise that 'Sunday after the war' is a device to keep them quiet for a few years.

These remarks apply to many reports and especially the Platt, Court, and Short reports. The reports on the training of senior and clinical medical officers are developing ominous signs of the same destiny. Our columns have recently shown evidence that unless there is an increase in consultant paediatrician posts many well trained junior staff have no prospects of attaining definitive posts. Less than a year ago we were reassured that the number of consultant posts would be increased by a substantial proportion before the end of this century. The latest cuts in staffing within the National Health Service show that this will not be attained. Why do we still cling to the illusion that there is a 'Sunday after the war'? 